\title{
Game Edukasi Berbasis Android sebagai Media Pembelajaran Matematika untuk Anak Tunarungu
}

\author{
Rizki Yusliana Bakti \\ Program Studi Informatika \\ Universitas Muhammadiyah Makassar \\ Makassar, Indonesia \\ rizkiyusliana@unismuh.ac.id \\ Muhyiddin A M Hayat \\ Program Studi Informatika \\ Universitas Muhammadiyah Makassar \\ Makassar, Indonesia \\ muhyiddin@unismuh.ac.id
}

\author{
Titin Wahyuni \\ Program Studi Informatika \\ Universitas Muhammadiyah Makassar \\ Makassar, Indonesia \\ titinwahyuni@unismuh.ac.id \\ Ridwang \\ Prodi Teknik Elektro \\ Universitas Muhammadiyah Makassar \\ Makassar, Indonesia \\ ridwang@unismuh.ac.id
}

\begin{abstract}
Education is a right for every individual. Not only those with normal conditions, but also those with special needs such as the deaf. Limited intellectual ability in deaf children has consequences for their difficulties in attending academic lessons including maths lessons. This research aims to create an application as a learning medium to attract deaf children in developing their intelligence. This application was created as a means to provide convenience to deaf children in helping the learning process of mathematics. This study uses observation data collection methods, interviews/questionnaires and library studies. Metode perancangan yang digunakan adalah waterfall dan teknik pengujian yang digunakan adalah Integration and Sistem testing. The result of this study is an android-based game application named math games. The test results show that this application is easy to learn and there are media that make children happy.
\end{abstract}

Keywords-Applications; Mathematics; Deaf; Android; Game Maker

\section{PENDAhUluan}

Pada dasarnya pendidikan memiliki peranan yang sangat penting, bukan hanya untuk masyarakat yang memiliki kelas ekonomi tinggi namun berlaku juga untuk masyarakat pada umumnya. Hal ini disebabkan karena pendidikan bertujuan untuk mencerdaskan kehidupan bangsa dan dapat membuat negara ini menjadi negara yang lebih maju seperti negara maju lainnya. Pendidikan adalah hal yang sangat penting bagi setiap manusia terutama bagi anak-anak. Begitu pentingnya pendidikan, sehingga perlu diterapkan model pendidikan kepada anak sedini mungkin agar dapat menentukan keberhasilan yang akan diraihnya dimasa mendatang.

Pendidikan merupakan hak bagi setiap individu. Tidak hanya mereka yang memiliki kondisi normal saja, tetapi juga bagi mereka yang memiliki kebutuhan khusus. Hak atas pendidikan bagi anak berkebutuhan khusus atau anak dengan hambatan diterangkan dalam UU No. 20 Tahun 2003 tentang Sistem Pendidikan Nasional Pasal 5 Ayat 2, yaitu "Warga Negara yang memiliki kelainan fisik, emosional, mental, intelektual dan/atau sosial berhak memperoleh pendidikan khusus". Berlandaskan pada Undang-undang tersebut, dapat disimpulkan bahwa semua warga Negara Indonesia tanpa terkecuali, seperti anak berkebutuhan khusus $(\mathrm{ABK})$ berhak memperoleh pendidikan yang layak [1]. Siswa tunarungu merupakan salah satu kelompok yang disebut sebagai berkebutuhan khusus. Siswa tunarungu adalah siswa yang kehilangan sebagian atau seluruh daya pendengarannya, sehingga mereka mengalami kesulitan dalam melakukan komunikasi. Kesulitan komunikasi tersebut sering menjadi hambatan dalam beradaptasi dan belajar. Oleh sebab itu, siswa tunarungu membutuhkan bimbingan sosial atau penanganan khusus [2].

Sesuai informasi yang kita ketahui bahwa banyak anak anak normal yang mengeluh dalam pelajaran matematika karena merupakan mata pelajaran yang cukup sulit, begitu juga dengan anak tunarungu. Terbatasnya kemampuan intelektual pada anak tunarungu membawa konsekuensi pada kesulitan mereka dalam mengikuti pelajaran akademik termasuk pelajaran matematika. Gesture menjadi salah satu upaya yang dilakukan dalam mentransfer ilmu pengetahuan agar dapat ditangkap maksudnya oleh siswa tunarungu. Sehingga dalam pembelajaran matematika, siswa tunarungu menggunakan Gesture sebagai alat komunikasi dan berinteraksi baik terhadap guru maupun teman sebayanya. Menurut Achadiyah dalam tulisan Kurnianingsih, Gesture berperan sebagai fasilitator dalam menyelesaikan masalah matematis [2].

Jika dibandingkan dengan materi pelajaran, permainan lebih diminati oleh setiap orang. Permainan yang banyak menyita perhatian siswa adalah game, baik game online maupun game offline. Citra game di masyarakat masih dipandang sebagai media penghibur bahkan ada sebagian orang menganggapnya sebagai media yang membuang waktu dibanding sebagai media pembelajaran. Padahal aplikasi game yang apabila dimaksimalkan, dapat menjadi sesuatu yang sangat berguna. Game harus memiliki desain 
antarmuka yang interaktif dan mengandung unsur menyenangkan.

Terrel dan Rendulic dalam penelitiannya menyatakan bahwa menggunakan game untuk belajar disekolah dasar dapat meningkatkan motivasi internal dan prestasi belajar siswa. Game edukasi yang dibuat, harus bisa merangsang motivasi belajar siswa dan membuat proses belajar lebih menyenangkan [3]. Di era teknologi saat ini, hampir semua orang menggunakan Smartphone dalam kehidupan sehari-hari. Smartphone dengan OS Android memberikan kelebihan dari segi fleksibilitas. Hal ini memungkinkan setiap orang mampu mengoperasikannya termasuk penyandang tuna rungu [4]. Maka dari itu dibuatkan media pembelajaran dengan memanfaatkan teknologi berupa game edukasi berbasis android untuk mata pelajaran matematika agar menarik minat anak anak tunarungu dalam mengembangkan kecerdasan yang dimilikinya.

\section{TEORI DASAR}

\section{A. Game Edukasi}

Game yang memiliki konten pendidikan lebih kenal dengan istilah game edukasi. Game berjenis edukasi ini bertujuan untung memancing minat belajar anak terhadap materi pelajaran sambil bermain, sehingga dengan perasaan senang diharapkan anak bisa lebih mudah memahami materi pelajaran yang disajikan. Jenis ini sebenarnya lebih mengacu kepada isi dan tujuan game, bukan jenis yang sesungguhnya. Game sanngat berpotensi untuk menumbuhkan kembali motivasi belajar anak yang mengalami penurunan. Tercatat bahwa pemakaian game sangat bermanfaat pada materi materi yang berhubungan dengan matematika, pendidikan pancasila dan kewarganegaraan, fisika dan kemampuan berbahsa seperti sosaial, biologi dan logika [5].

Dalam penelitian yang dilakukan Rais mengatakan bahwa ada beberapa kriteria game edukasi menurut Hurd dan Jenuing, perancangan yang baik haruslah memenuhi kriteria dari education game itu sendiri [3]. Berikut ini adalah beberapa kriteria dari sebuah education game, yaitu:

- Nilai keseluruhan (Overall value)

Nilai keseluruhan dari suatu game terpusat pada desain dan panjang durasi game.

- Dapat digunakan (Usability)

Mudah digunakan dan diakses adalah poin penting bagi pembuat game

- Keakuratan (Accuraty)

Keakuratan diartikan sebagaimana kesuksesan model/gambaran sebuah game dapat dituangkan ke dalam percobaan atau perancangannya.

- Kesesuaian (Appropriteness)

Kesesuaian dapat diartikan sebagaiamana isi dan desain game dapat diadaptasikan terhadap keperluan user dengan baik.

- Relevan (Relevance)

Dapat mengaplikasikan isi game ke target user. Agar dapat relevan terhadap user, sistem harus membimbing dalam pencapaian tujuan pembelajaran.

- Objektifitas (Objectives)

Objektifitas menentukan tujuan user dan kriteria dari kesuksesan atau kegagalan.

- Umpan balik (Feedback) membantu pemahaman user bahwa permainan (performace) sesuai dengan objek game atau tidak, feedback harus disediakan.

\section{B. Android}

Android adalah sistem operasi berbasis Linux yang dirancang untuk perangkat seluler layar sentuh seperti telepon pintar dan komputer tablet. Android awalnya dikembangkan oleh Android, inc. Dengan dukungan finansial dari Google yang kemudian membelinya pada tahun 2005. Sistem operasi ini dirilis secara resmi pada tahun 2007. Bersamaan dengan didirikannya Open Handset Alliance, konsorsium dari perusahaan-perusahaan perangkat keras, perangkat lunak, dan telekomunikasi yang bertujuan untuk memajukan standar terbuka perangkat seluler. Ponsel Android pertama mulai dijual pada bulan Oktober 2008 [6].

\section{Tunarungu}

Tunarungu dapat diartikan sebagai suatu keadaan kehilangan pendengaran yang mengakibatkan seseorang tidak dapat menangkap berbagai rangsangan, terutama melalui indera pendengaran. Anak tunarungu juga diartikan sebagai mereka yang kehilangan pendengaran baik sebagian maupun keseluruhannya yang menyebabkan pendengarannya tidak memiliki nilai fungsional di dalam kehidupan sehari-hari. Tunarungu adalah istilah umum yang digunakan untuk menyebut kondisi seorang yang mengalami gangguan dalam indra pendengaran. Pada anak tunarungu, tidak hanya gangguan pendengaran saja yang menjadi kekurangannya. Kemampuan berbicara seseorang dipengaruhi seberapa sering dia mendengarkan pembicaraan, mamun dikarenakan anak tunarungu tidak bisa mendengarkan apapun sehingga di sulit mengerti percakapan yag dilakukan oleh orang lain, maka dari itu mereka harus menggunakan bahasa isyarat agar mengerti satu sam lain [7].

\section{Matematika}

Matematika merupakan salah satu ilmu pendidikan yang utama karena matematika berperan dalam melengkapi ilmu lainnya. Oleh karena itu pendidikan matematika menjadi salah satu pusat perhatian kualitas pendidikan di Indonesia sehingga muncullah banyak upaya untuk memperbaiki kualitas pendidkian matematika. Ketika berbicara mengenai pendidikan maka pembelajaran adalah hal yang paling berkaitan dengan pendidikan. Dalam berlangsungnya proses pembelajaran sering sekali siswa menemukan objek yang bersifat abstrak terutama dalam pembelajran matematika dimana abstrak merupakan salah satu karakteristikanya. Hal ini menyebabkan siswa merasa kesulitan dalam 
memaknai hal-hal yang abstrak kepada kehidupan nyata dan menyampaikan ide-ide dalam matematika baik secara lisan maupun tulisan. Menurut Jenning dan Dunne mengatakan bahwa, "kebanyakan siswa mengalami kesulitan dalam mengaplikasikan matematika dalam kehidupan nyata" [3].

Mata pelajaran matematika yang diberikan kepada siswa tunarungu tak jauh berbeda dengan yang diberikan kepada siswa normal karena diberikan untuk membekali siswa agar mampu berfikir logis, analitis, sistematis, kritis, kreatif, dan mempunyai kemampuan bekerjasama. Kompetensi tersebut diperlukan agar siswa dapat memiliki kemampuan memperoleh, mengelola, dan memanfaatkan informasi untuk bertahan hidup pada keadaan yang selalu berubah, tidak pasti, dan kompetitif. Hal ini disebabkan karena matematika merupakan ilmu universal yang mendasari perkembangan teknologi modern, mempunyai peran penting dalam berbagai disiplin ilmu dan memajukan daya pikir manusia [8].

\section{Metode PENELITIAN}

Jenis penelitian ini adalah penelitian pengembangan. Model penelitian pengembangan yang digunakan adalah 4-D, yang terdiri atas empat tahapan utama, yaitu pendefinisian, perancangan, pengembangan, dan penyebaran. Penelitian dilakukan sampai tahap akhir berupa aplikasi game yang sudah bisa digunakan, di mana diperoleh aplikasi Android berupa game berbasis Android untuk pembelajaran Matematika bagi Siswa Sekolah Luar Biasa (SLB) yang sudah dievaluasi para ahli dan diuji coba. Tahap terakhir, yaitu penyebaran tidak dilakukan berdasarkan pertimbangan bahwa untuk melaksanakan tahap ini diperlukan keterlibatan banyak siswa dan sekolah yang berbeda. Instrumen pengumpulan data yang digunakan dalam penelitian ini, antara lain angket validasi ahli media, ahli materi, ahli desain pembelajaran, angket respons peserta didik, dan angket respons guru. Indikator penilaian pada angket respons siswa dan guru menggunakan lima skala penilaian, yaitu sangat baik (skor 5), baik (skor 4), cukup (sekor 3), kurang (skor 2), dan sangat kurang (skor 1). Indikator penilaian pada angket validasi ahli media, ahli materi, ahli desain pembelajaran. Sebelum digunakan, semua instrumen tersebut telah diuji validitas isinya oleh dua orang validator, yaitu 1 orang dosen dari Jurusan Pendidikan Matematika Universitas Muhammadiyah Makassar.

Validitas dari multimedia pembelajaran yang dikembangkan dalam penelitian ini ditentukan berdasarkan hasil penilaian 5 orang ahli, yaitu satu orang dosen ahli Jurusan Teknik Elektro sebagai ahli media, satu orang dosen Jurusan Pendidikan Matematika Universitas Muhammadiyah Makassar sebagai ahli materi, satu orang ahli dosen Informatika desain pembelajaran, dua guru SLB sebagai ahli materi dan bahasa. Kepraktisan multimedia pembelajaran yang dikembangkan dalam penelitian ini diukur berdasarkan keterlaksanaan media tersebut di kelas uji coba. Kelas uji coba terdiri dari 5 orang siswa kelas I SLB Lamuru. Data mengenai kepraktisan multimedia pembelajaran diperoleh dari angket respons siswa dan respons guru terhadap multimedia pembelajaran yang dikembangkan. Teknik analisis data yang digunakan dalam penelitian ini adalah teknik analisis data kualitatif dan deskriptif kuantitatif. Teknik analisis data kualitatif digunakan untuk mengelola data hasil review ahli media, ahli materi, ahli desain pembelajaran, ahli bahasa, respons siswa dan respons guru. Hasil data ini kemudian digunakan untuk merevisi produk yang dikembangkan. Teknik analisis data deskriptif kuantitatif digunakan untuk mengelola data hasil angket validasi, angket respons siswa, respons guru, dan hasil tes evaluasi. Hasil analisis data ini kemudian digunakan untuk mengetahui validitas dan kepraktisan multimedia pembelajaran yang dikembangkan.

\section{HASIL DAN PEMBAHASAN}

Output dari penelitian ini yaitu sebuah aplikasi game berbasis android Berikut ini beberapa tampilan interface dari aplikasi yang telah di implementasikan:

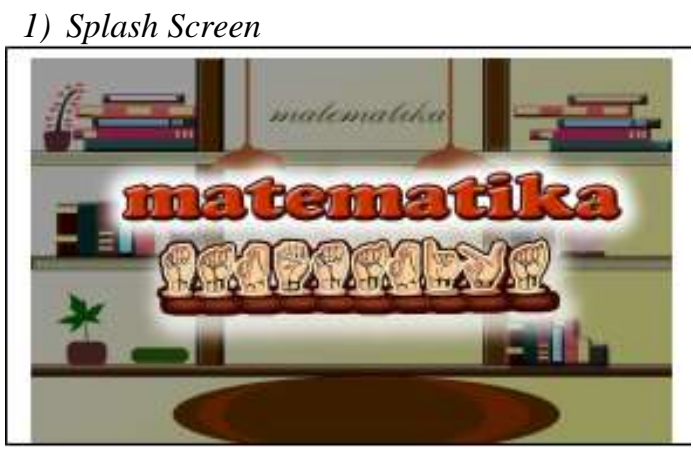

Gambar 1. Halaman awal aplikasi

Splash screen merupakan halaman awal aplikasi yang berisi logo aplikasi ketika memulai dan membuka aplikasi seperti. Pada saat pertama kali membuka aplikasi akan muncul gambar tangan yang merupakan isyarat untuk angka 1 sampai 10 seperti yang diperlihatkan gambar 1. Ini digunakan untuk memudahkan anak tunarungu untuk mengetahui angka yang akan digunakan pada aplikasi. Tampilan pada halaman awal ini juga digunakan untuk menggambarkan jenis permainan yang akan ditampilkan pada aplikasi game.

2) Menu Utama

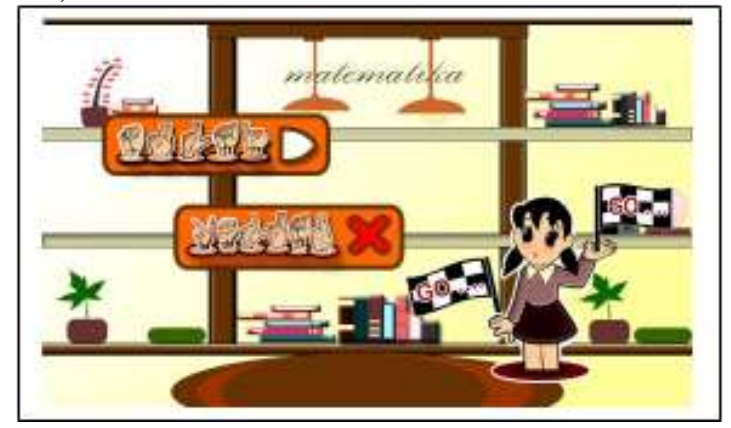

Gambar 2. Menu utama 
Menu utama merupakan halaman yang berisi tombol mulai, tombol keluar dan tombol musik seperti yang ditunjukkan pada gambar 2. Pada halaman utama aplikasi, tombol mulai disimbolkan dengan gambar tangan yang merupakan isyarat berupa tulisan "MULAI" dan simbol segitiga yang fungsinya untuk memulai game. Selain itu terdapat tombol keluar yang disimbolkan dengan gambar tangan yang merupakan isyarat berupa tulisan "KELUAR" dan simbol silang yang fungsinya untuk keluar dari aplikasi game.

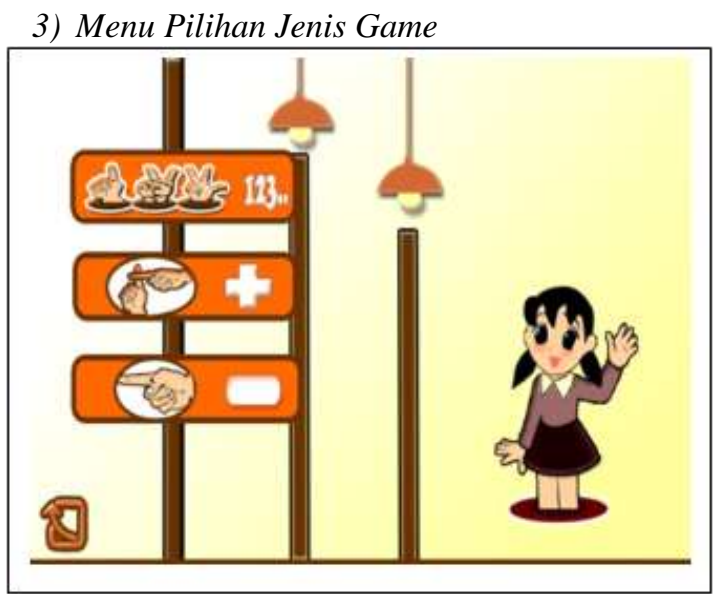

Gambar 3. Menu pilihan jenis game

Setelah menekan tombol "MULAI" maka aplikasi akan membuka halaman menu pilihan jenis game. Pada halaman ini berisi tombol untuk memilih jenis permainan dan tombol kembali, dimana jenis permainan ada tiga yaitu tombol "PENGENALAN ANGKA", "PENJUMLAHAN", dan "PENGURANGAN", serta tombol kembali untuk kembali ke menu sebelumnya seperti yang ditunjukkan pada gambar 3 .

4) Menu Pengenalan Angka

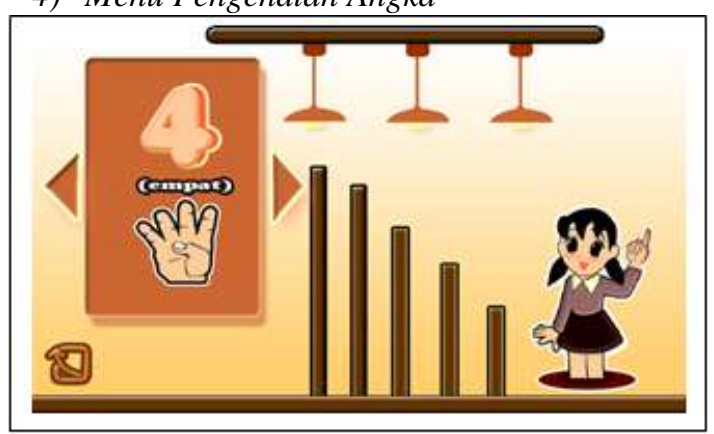

Gambar 4. Menu Pengenalan Angka

Setelah menekan tombol "PENGENALAN ANGKA" maka aplikasi akan membuka halaman menu pengenalan angka seperti yang ditunjukkan gambar 4. Halaman ini dibuat dengan menampilkan beberapa angka disertai dengan symbol isyarat untuk mempermudah dalam pembelajaran matematika anak Tunarungu.
5) Menu Pilih Level

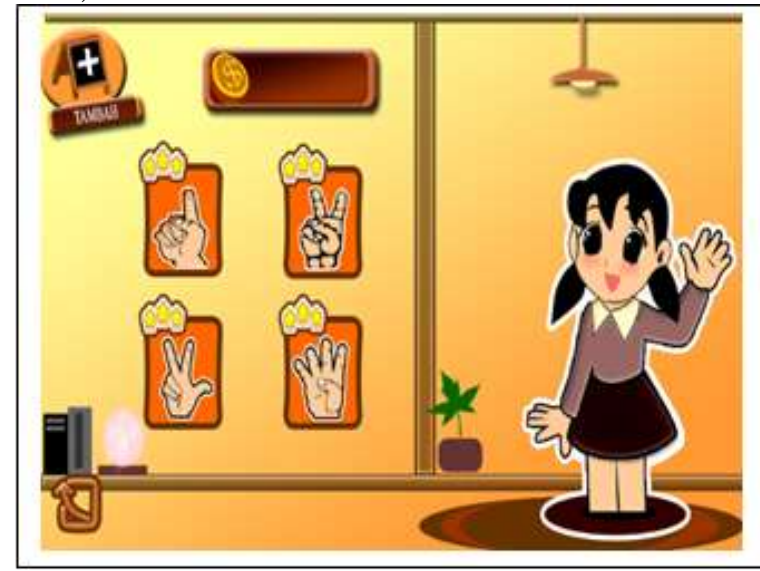

Gambar 5. Menu pilih level

Setelah memilih tombol "PENJUMLAHAN" atau "PENGURANGAN" pada menu pilihan jenis game, maka aplikasi akan membuka halaman pilih level seperti pada gambar 5. Pada halaman ini berisi tombol "KEMBALI", dan tombol memilih level 1, 2, 3 dan 4. Setiap level akan terbuka secara bertahap apabila pengguna telah menyelesaikan permainan pada level sebelumnya, dan tombol kembali digunakan untuk kembali ke halaman utama.

\section{6) Menu Penjumlahan dan pengurangan}

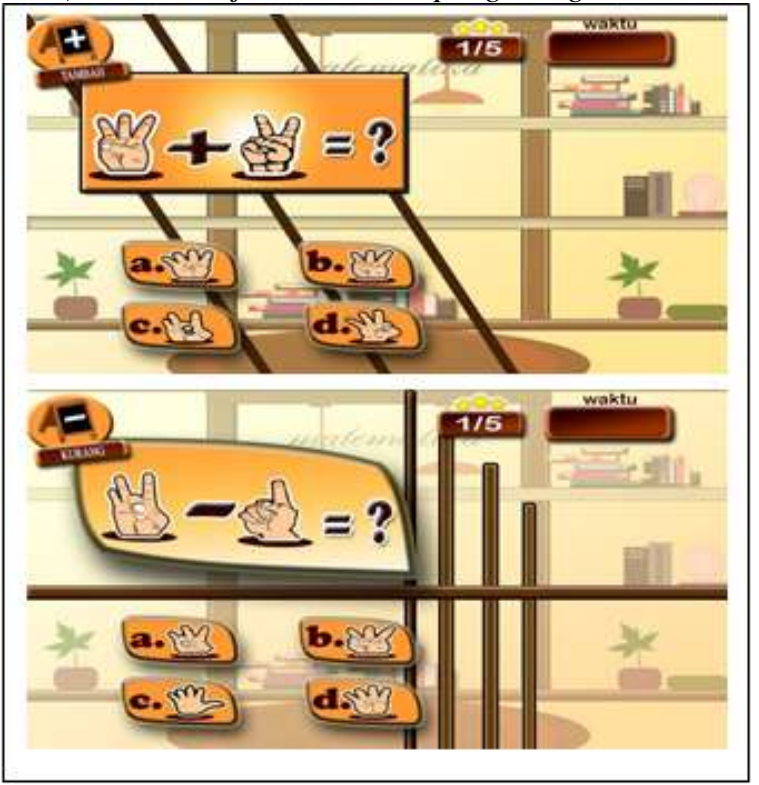

Gambar 6. Menu penjumlahan dan pengurangan

Gambar 6 menunjukkan halaman pada menu "PENJUMLAHAN" dan "PENGURANGAN". Pada halaman ini dibuat seperti soal multiple choice dimana pengguna harus menjawab soal untuk mendapatkan score terbaik sesuai dengan waktu yang telah ditentukan untuk melanjutkan ke level selanjutnya. Apabila user tidak dapat menjawab pertanyaan yang telah disiapkan maka permainan akan kembali ke awal. 
7) Tampilan Score

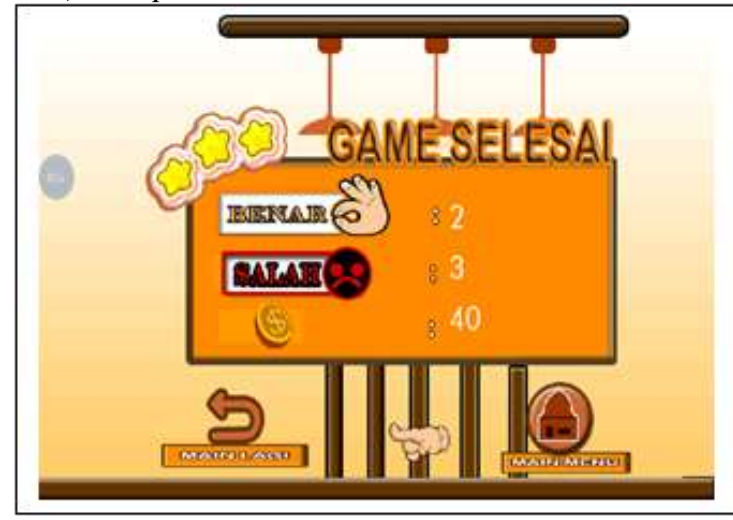

Gambar 7. Tampilan score

Setelah mengerjakan soal pada menu "PENJUMLAHAN" atau "PENGURANGAN" maka aplikasi akan menampilkan halaman tampilan score seperti yang ditunjukkan gambar 7. Halaman ini dibuat untuk menampilkan score yang telah didapatkan dalam menyelesaikan permainan disetiap level.

\section{8) Tampilan Game Over}

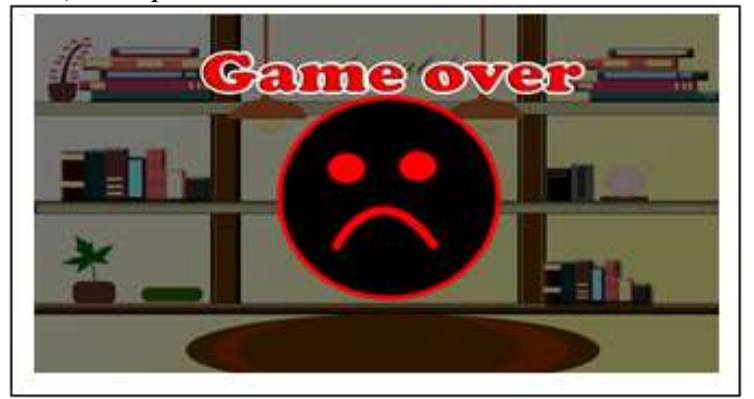

Gambar 8. Tampilan Game Over

Aplikasi akan menampilkan halaman game over ketika pemain tidak pernah mendapatkan score 5 sebanyak 3 kali berturut turut. Halaman ini menampilkan gambar sedih yang menandakan bahwa pemain gagal dalam menyelesaikan permainan seperti yang ditunjukkan gambar 8 .

\section{KesIMPULAN}

Berdasarkan implementasi dan hasil pengujian yang telah dilakukan, serta hasil kuisioner yang telah disebarkan, maka dapat ditarik kesimpulan bahwa aplikasi ini berjalan sesuai fungsinya. Dari responden menyatakan bahwa game yang dibuat ini dapat menarik minat belajar anak anak karena di dalam game ini terdapat media yang membuat anak anak senang. Game ini sangat direkomendasikan untuk dikembangkan lebih lanjut lagi. Aplikasi ini berjalan pada Smartphone berbasis android yang pada dasarnya merupakan game edukasi yang diharapkan mampu menambah pengetahuan khususnya untuk anak anak yang berkebutuhan khusus seperti anak tunarungu dalam mempelajari pelajarn matematika.
Game edukasi ini bukan hanya sekedar untuk mencari kesenangan, tapi juga untuk bermain sambil belajar karena di dalamnya terdapat konten media yang bermanfaat dalam melatih pembelajaran matematika anak tunarungu. Aplikasi ini memiliki kekurangan yaitu dari banyaknya proses pembelajaran matematika dibidang akademik, pembuat hanya mengambil beberapa contoh soal untuk dimasukkan kedalam game.

\section{UCAPAN TERIMA KASIH}

Penelitian ini merupakan penelitian yang didanai oleh Universitas Muhammadiyah Makassar dengan skema Penelitian Dosen Pemula 2020. Ucapan terima kasih diberikan kepada Lembaga Penelitian dan Pengabdian Masyarakat, Universitas Muhammadiyah Makassar atas kesempatan yang diberikan. Semoga penelitian ini membawa kemanfaatan untuk Universitas Muhammadiyah Makassar.

\section{REFERENCES}

[1] A. F. Rahman and S. Sulthoni, "Kegiatan Membaca Pagi untuk Mengembangkan Kemampuan Oral Siswa Tunarungu," J. ORTOPEDAGOGIA, vol. 3, no. 2, pp. 76-80, 2017.

[2] M. D. Kurniasih, H. Darojati, S. B. Waluya, and R. Rochmad, "Analisis Gesture Siswa Tunarungu dalam Belajar Matematika di Tinjau dari Gender," JKPM (Jurnal Kaji. Pendidik. Mat., vol. 5, no. 2, pp. 175-182, 2020.

[3] L. M. Rais, "Rancang Bangun Aplikasi Game Math Race Berbasis Android,” Universitas Islam Negeri Alauddin, 2017.

[4] I. K. W. Ita Kumala Wardani, "Perancangan Tutorial Bahasa Isyarat Berbasis Android bagi Anak Tunga Rungu," Sekolah Tinggi Informatika dan Komputer, 2016.

[5] Ahsan, "Game Pengenalan Makanan Tradisional Khas Sulawesi Selatan Berbasis Android," Universitas Islam Negeri Alauddin, 2015.

[6] I. Rahmadani, "Rancang Bangun Aplikasi Game Edukasi Bahasa Bugis dan Bahasa Makassar Berbasis Android," Universitas Islam Negeri Alauddin, 2017.

[7] N. Martiasari, "Pendidikan Agama Islam Pada Anak Tunarungu Di SLB-B Ngudi Hayu Srengat Blitar,” 2015.

[8] Mulyadi, "Pembelajaran Matematika di Sekolah Luar Biasa (SLB) Khusus Tunarungu Karnnamanohara Yogyakarta Tingkat SMP,” Universitas Negeri Yogyakarta, 2015.

Lisensi Creative Commons Attribution 4.0 International Licensi 